\title{
LETRAMENTO LITERÁRIO E A CONTAÇÃO DE HISTÓRIAS NO ENSINO SUPERIOR: A LEITURA DO TEXTO POÉTICO COMO UM PROCESSO DIALÓGICO
}

\author{
Ronaldo Gomes dos Santos (Graduando em letras UNEAL) ${ }^{1}$ \\ Orientadora: Dra. Amanda Ramalho de Freitas Brito (UFPB) ${ }^{2}$
}

RESUMO: O presente artigo insere-se no âmbito de reflexões sobre o texto poético em sala de aula a partir da leitura crítica e da recepção de poemas apresentados pela perspectiva da contação de histórias. A contação de histórias sempre teve um papel determinante na educação e no processo de assimilação do texto literário, e em sociedades antigas representava o eixo central de transmissão de valores através da narrativa oral, como se deu na África do poeta Amadou Ampâté Bá. Muitos textos literários participaram do processo de contação de história, transformando-se em canto ou discurso vocal, transmitido oralmente pelo povo, como aconteceu com a Divina Comédia, de Dante Alighieri, o que aponta Zumthor (2010) ao falar das travessias entre escrita e oralidade. Nesse sentido, procuramos pensar a contação de história como um processo dialógico, que permite ao aluno o conhecimento dos textos poéticos em suas dimensões estéticas, históricas e intersemióticas, posto que uma das características do discurso poético é a sua remissão densa a outros discursos, criando em torno do discurso poético um espaço múltiplo de apreensão, ou seja, um espaço intertextual. Tal espaço reverbera, além das citações diretas e indiretas, um diálogo com temas e signos de modo a gerar em cada novo texto um aprofundamento ou reelaboração de sentido. Por isso, como parte do processo de contação de histórias procuramos mostrar de que modo a poesia pode ser incorporada ou recriada por outras mídias, destacando os vários modos de contar histórias. Para a realização dessa pesquisa, nosso método se baseou no viés crítico-teórico de Kleiman (1989), que ao falar sobre o ensino de leitura, destaca que se faz necessário pensar a relação entre teoria e prática a partir da proposta de leitura como interação de processos. Esse viés teórico colabora para a formação crítica do leitor de literatura do curso de Letras, já que o coloca diante das várias possibilidades de compreensão de um tema ou de fatores e espaços locais, figurando o caráter universal da literatura e da história. Há nesse percurso dialógico de leitura e contação de histórias tanto o letramento literário quanto a humanização do leitor. Dessa forma, fizemos um recorte da pesquisa desenvolvida na Universidade Estadual de Alagoas, nas turmas de Crítica Literária e de Literatura Comparada, considerando a contação de histórias em sala de aula por meio da relação entre textos da oralidade, textos escritos e texto fílmico.

\footnotetext{
${ }^{1}$ Esse artigo é um recorte de uma pesquisa que foi desenvolvida no campus IV da Universidade Estadual de Alagoas, integrante do projeto de PIBIC/ FAPEAL, intitulado Letramento literário e a contação de histórias no ensino superior: a leitura do texto poético como um processo dialógico. Projeto desenvolvido junto ao grupo de pesquisa GELIC. E-mail: ronaldogomer123@gmail.com

2 Professora de Literaturas de Língua Portuguesa da Universidade Federal da Paraíba. Coordenadora do Grupo de Estudos em Literatura, Intersemiose e Cultura (GELIC). Pesquisadora credenciada pelo CNPq e FAPEAL. E-mail: amandaramalhobrito@gmail.com.
} 
Palavras-chave: Contação de histórias; Intersemiótica; Discurso poético.

\section{Introdução}

Este trabalho é fruto de um recorte de nosso projeto de iniciação científica sobre o ensino de poesia, em sala de aula, pela perspectiva crítica da intertextualidade e pela perspectiva metodológica da contação de histórias. Destacamos como a pesquisa foi desenvolvida no campus IV da Universidade Estadual de Alagoas, e quais os pontos positivos da mesma enquanto abrangência acadêmica a partir das discussões geradas pelo desenvolvimento do projeto.

Diante disso, procurando compreender a contação de história como um processo dialógico que nos permite conhecer as dimensões estéticas, históricas, performáticas e intersemióticas do texto poético, sobretudo, de textos que trazem em sua tessitura aspectos configurativos da oralidade e do drama. Tendo em vista que a contação de história, consoante Matos (2005), se faz na contemporaneidade pela reconfiguração de temas ou estórias narradas anteriormente pela tradição oral ou por outros textos (literários, dramáticos, fílmicos, outros). As discussões foram pensadas em nosso escopo por meio da análise e apresentação, feita em sala de aula do curso de Letras da UNEAL com alunos de Literatura Brasileira, de poemas contemporâneos: Na rua do sabão (Manuel Bandeira) e sua relação com a cantiga popular Cai cai balão, mostrando a oralidade enquanto significação da escrita e por meio da leitura comparativa entre o poema Morte e Vida Severina e sua adaptação para a TV Escola, dirigido por Afonso Serpa. Nosso intuito foi mostrar como uma história pode ser incorporada ou recriada por outras mídias, destacando os vários modos de se narrar e contar histórias.

Como ressaltou Kristeva (2005), uma das características do discurso poético é a sua remissão densa a outros discursos, criando em torno do discurso poético um espaço múltiplo de apreensão, ou seja, um espaço intertextual. Tal espaço reverbera, além das citações diretas e indiretas, um diálogo com temas e signos de modo a gerar em cada novo texto um aprofundamento ou reelaboração de sentido.

Essa pesquisa surge com o intuito de pensar a linguagem poética como um discurso de intermedialidade, já que a poesia desde as suas origens mantém um vínculo com outras 
linguagens: as artes plásticas, a dança e a música. Esse transcurso reforça o letramento literário, uma vez que coloca o leitor em uma situação de vivência profunda com a poesia através de uma prática dialética do conhecimento estético e histórico do texto poético. A poesia contemporânea resgata esse caráter de intermedialidade da poesia por meio dos vários espaços de implementação da mesma, que para além do livro se revela na música, no cinema e na performance (voz e gestos), daí a relevância da contação de história no processo de reflexão e assimilação do texto poético.

Desse modo, nossa proposta procura inserir os estudantes de letras no campo teóricoanalítico das pesquisas acerca da leitura e compreensão do gênero lírico (poesia) na fronteira do diálogo com outras linguagens e mídias como mecanismo de interpretação e ensino de Literatura. Ressaltando ainda o aspecto lúdico dessa relação por meio da contação de histórias. Essa reverberação do lúdico através das histórias promove o letramento literário, pois reflete as dimensões do homem através da imagem simbólica dos objetos em diferentes espaços de representação, criando assim um alargamento da própria experiência.

Nosso método fundamentou-se nos pressupostos de Kleiman (1989), que ao falar sobre o ensino de leitura, destaca que se faz necessário pensar a relação entre teoria e prática a partir da proposta de leitura como interação de processos: "as propostas interativas, cujas predições são testadas em grande parte das pesquisas empíricas realizadas hoje, alcançam um maior grau de especificidade relativa à natureza dos processos envolvidos na leitura, e à relação entre eles, aproveitando as contribuições de várias disciplinas." (KLEIMAN, 1989, p.30).

Sendo assim, nossa pesquisa, selecionou um percurso metodológico pautado em três significativos momentos: o primeiro consistiu na leitura dos postulados teóricos que nortearam o nosso trabalho, e ainda em uma extensa pesquisa bibliográfica, que contribuiu para enriquecer a nossa análise final. $\mathrm{O}$ segundo momento incidiu sobre a análise comparativa dos textos envolvidos no corpus de nossa análise: o poema $\mathrm{Na}$ rua do Sabão, de Manuel Bandeira, publicado no livro Ritmo Dissoluto (1924) e a cantiga popular Cai cai balão. Além do poema Morte e Vida Severina, de João Cabral de Melo Neto (1955) e sua adaptação de mesmo nome, dirigida por Afonso Serpa. Destacando-se a relação intersemiótica e dialógica entre os textos, em um processo de reconfiguração do tema e dos textos primários, percurso que atravessa em nossa leitura a palavra do contador de história (o poeta e o cineasta), renovada e atualizada em um imbricamento de linguagens que nos dá acesso às várias 
camadas de significação do texto literário. Essa etapa considerada analítico-interpretativa, leva em consideração os pressupostos teóricos de Bakhtin (2002); Plaza (2003) e Kristeva (2005). O terceiro momento foi refletido pela pesquisa de campo, dividida em aulas práticas e uma oficina de Teatro.

As aulas práticas sobre o Corpus de análise se estruturou em uma perspectiva dialógica, na qual se toma o texto literário como espaço de implementação da contação de histórias e, por sua vez, do processo de letramento literário, investigado reflexivamente por meio de questionários e descrições das duas aulas sobre os poemas.

\section{Interfaces do Texto Poético na Sala de Aula: Tradução e Contação de Histórias}

O letramento literário é diferente dos outros tipos de letramento porque a literatura ocupa um lugar único em relação à linguagem, ou seja, cabe à literatura por meio do trabalhado efetuado com o significante, apresentar outras leituras da sociedade e de questões fundamentais que participam da nossa fusão com o outro. O letramento feito com textos literários proporciona um modo privilegiado de inserção no mundo da escrita, posto que conduz ao domínio do mundo por meio da palavra, a partir dela mesma. Finalmente, o letramento literário precisa do espaço acadêmico ou da escolar para se concretizar, isto é, ele demanda um processo educativo específico que a mera prática de leitura de textos literários não consegue sozinha efetivar.

É por entender essa singularidade que se define o letramento literário como “[...] o processo de apropriação da literatura enquanto construção literária de sentidos" (PAULINO; COSSON, 2009, p. 67). Nessa definição, é importante compreender que o letramento literário é bem mais do que uma habilidade pronta e acabada de ler textos literários, pois requer uma atualização permanente do leitor em relação ao universo literário e crítico.

Esse letramento não é apenas um saber que se adquire sobre a literatura ou os textos literários, mas sim uma experiência de dar sentido ao mundo por meio de palavras que falam de palavras, transcendendo os limites de tempo e espaço. O letramento literário é, pois, capaz 
de tornar o mundo compreensível, ou seja, permite saber da vida transformando as palavras em narrativas e poesia. Conforme Cosson (2006):

\begin{abstract}
O letramento literário, conforme concebemos possui uma configuração especial, pela própria condição de existência da escrita literária. O processo de letramento que se faz via textos literários compreende não apenas uma dimensão diferenciada do uso social da escrita, mas também, e sobretudo, uma forma de assegurar seu efetivo domínio. Daí sua importância na escola, ou melhor, sua importância em qualquer processo de letramento, seja aquele oferecido na escola, seja aquele que se encontra difuso na sociedade (COSSON, 2006 p. 12).
\end{abstract}

A difícil tarefa da escola de alfabetizar e letrar seus estudantes faz com que professores busquem soluções para amenizar essa dificuldade e nessa tentativa, se faz necessário um olhar especial para o texto poético, pouco trabalhado nas escolas. Ao analisar a utilização de poemas nos manuais escolares, Pinheiro (2005, p.62), afirma: "enquanto não se compreender que a poesia tem um valor, que não se trata apenas de um joguinho ingênuo com palavras, ela continuará a ser tratada como gênero menor e, pior ainda, continuará a ser um dos gêneros literários menos apreciados no espaço escolar."

A poesia é capaz de exprimir o que não está dito, é capaz de condensar sentidos de forma que apenas um leitor crítico e reflexivo é capaz de compreender. Por isso, a poesia se faz um instrumento valioso nas mãos do professor que deseja que seu estudante seja capaz de ter domínio sobre as palavras e desta forma, busque interagir com o mundo que o cerca tendo consciência de que é preciso apossar-se da leitura e da escrita como instrumentos de transformação e mais do que isso, de sobrevivência em meio a uma sociedade letrada em que o uso das palavras é imperioso.

Diante das questões reverberadas anteriormente, procuramos refletir o processo de letramento literário na Universidade através da contação de histórias em sala de aula por meio da relação entre textos da oralidade e textos escritos. Destacando que essa leitura comparativa é ressoada por meio da tensão de olhares, cujo movimento ressignifica continuamente o objeto, O que remete para o conceito de dialogismo bakhtiniano:

O contexto que avoluma a palavra de outrem origina um fundo dialógico cuja influência pode ser muito grande. Recorrendo a procedimentos de enquadramento apropriados, pode-se conseguir transformações notáveis de 
um enunciado alheio (...). No campo de quase todo enunciado ocorre uma interação tensa e um conflito entre sua palavra e a de outrem, um processo de delimitação ou de esclarecimento dialógico mútuo. (BAKHTIN, 2002, p.78 e 90$)$.

Esse viés teórico colabora para a formação crítica do leitor de literatura do curso de Letras, já que o coloca diante das várias possibilidades de compreensão de um tema ou de fatores e espaços locais, figurando o caráter universal da literatura e da história. Há nesse percurso dialógico de leitura e contação de histórias tanto o letramento literário quanto a humanização do leitor. Por isso é tão importante trazermos essa discursão sobre a atualidade da contação de histórias e suas contribuições.

A contação de histórias, em muitas sociedades antigas, repercutiu como meio de acesso ao conhecimento e a reflexão, e era transmitida geralmente pela tradição oral. Com a expansão urbana e industrial e com o advento da televisão, a contação oral das histórias se não deu lugar, passou a atravessar o universo do texto escrito. Segundo Matos (2005, p.116), "os novos contadores recriam a oralidade a partir de uma fonte escrita, e o processo de contar é totalmente diferente daquele de quando os contos chegam pelos ouvidos".

A função do contador de história, na sociedade contemporânea sofreu determinadas transformações, pois eles não recebem a palavra como herança direta de uma tradição oral, embora esses contadores se aproximem daqueles contadores das sociedades que em sentido lato se manifestavam por meio da linguagem oral. Os novos contadores de histórias recuperam as histórias vivas no imaginário popular, mas também histórias presentes em roteiros cinematográficos e em vários gêneros literários. Às vezes até utilizam recursos utilizados por essas manifestações mais novas de contação, como a performance cinematográfica e a representação do narrador heterodiegético ${ }^{3}$, elemento característico do romance. Esses novos contadores de histórias são os poetas, repentistas, contistas e cordelistas que reiteram os valores da tradição por meio do improviso musical ou da escrita. Essa função do contador se assemelha a relação que a literatura mantem com seus leitores.

De acordo com Cândido (1995), a literatura tem uma função primordial, humanizar o homem, pondo-o em um jogo dialético com a própria existência, assim, permitindo ao sujeito

\footnotetext{
${ }^{3}$ Narrador heterodiegético é uma expressão introduzida no domínio da narratologia por Genette (1989) para designar o narrador que não participa da história narrada, que se manifesta como um narrador de conhecimento ilimitado, representado no enredo por uma voz narrativa.
} 
enquanto leitor acessar uma consciência macroestrutural da vida. Por isso, o modo de ensinar a literatura em sala de aula é tão relevante para a formação crítica e humana do aluno, e deve focalizar, principalmente, a vivência e a interpretação do texto literário, posto aqui por meio da contação de histórias.

Esses percursos são geradores de uma leitura dialética, que estimula o acúmulo de conhecimento e, por conseguinte, o processo de compreensão e interpretação do texto literário, em decorrência do que chamamos de intersecção de memórias, fomentada pela relação do discurso poético com outros discursos.

$\mathrm{O}$ livro A arte de encantar o contador de histórias contemporâneo e seus olhares (2012), traz artigos de diversos narradores de várias partes do Brasil e também de outros países. Encontramos ali relatos riquíssimos para a prática da narração. Alguns artigos trazem histórias escolhidas a dedo pelos seus autores. Há experiências com contos em bibliotecas, na arte-educação, na mediação de leitura, com a memória afetiva, teatro e muito mais, como as experiências compartilhadas.

Assim, a forma como uma história é contada permite ao ouvinte uma gama de aprendizagens informais, na qual experiências passadas se mesclam com as experiências presentes, e aprendizagens formais em que o indivíduo, em especial a criança, aprende conteúdos associados a diversas áreas do conhecimento sem nem se dar conta. Segundo Abramovich (1997, p. 17):

É através duma história que se podem descobrir outros lugares, outros tempos, outros jeitos de agir e de ser, outra ética, outra ótica... É ficar sabendo História, Geografia, Filosofia, Política, Sociologia, sem precisar saber o nome disso tudo e muito menos achar que tem cara de aula... Porque, se tiver, deixa de ser literatura, deixa de ser prazer e passa a ser Didática que é outro departamento (não tão preocupado em abrir as portas da compreensão do mundo). (ABRAMOVICH, 1997, p.17).

Temos ali treze Olhares distintos de contadores de histórias contemporâneos e suas experiências. Cada um, ao seu modo, convida o leitor/narrador a refletir sobre sua prática. É a renovação de uma arte que encanta há tanto tempo e que precisa ser repensada sempre, fomentando a importância da contação de histórias na sociedade letrada do século XX e XXI. Dentro dessa perspectiva compreendemos o poema de Manuel Bandeira, escolhido como escopo de nossa pesquisa nesse eixo de reiteração das narrativas orais. 
Na rua do sabão foi publicado em 1924, no livro O Ritmo Dissoluto. Partindo de um refrão recuperado da cantiga popular Cai cai balão, Bandeira retoma imagens da sua infância, criando assim uma relação temporal das vivencias do autor.

Percebemos essa temporalidade no poema de Bandeira quando lemos Tradução Intersemiótica (2003), de Julio Praza, que demonstra na prática a teoria da Tradução Intersemiótica como um movimento que traça linhas formando tramas de interpretações e produção de significados, numa conversão de signos em outros signos. O que acontece na transposição de sentidos que é trazido da cantiga popular para o texto de Bandeira.

Neste sentido, Plaza (2003) analisa a contraposição entre história linear e mônada, ou seja, sem partes, bem como investiga as distintas formas e estratégias de operar sobre o passado, ou recuperá-lo, para se projetar o presente sobre o futuro, permitindo uma leitura que pode ir além do campo das artes plásticas. Essa estratégia de leitura, respaldada na contação de hsitórias por meio da tradução, enriquece a memória linguística e cultural do estudante de Letras, estabelecendo uma relação densa de leitura interpretativa das narrativas literárias.

A recepção dos textos em sala de aula (na Uneal), foi bem difícil, pois os alunos não estavam familiarizados com a contação de histórias e nem com a forma de adaptação apresentada. Porém com o decorrer da apresentação do projeto eles puderam perceber a relevância do estudo para formação de um bom profissional de Letras e até mesmo para formação cidadã. E como a função do contador é importante para manter nossa cultura.

$\mathrm{O}$ ato de contar história é difícil por que o contador deve ter uma desenvoltura peculiar, mais com trabalho e dedicação conseguimos perceber que o contador de história não só usa a oralidade para encantar o ouvinte, mas se apropria do corpo como representação dos atos e movimentos da história, traduzindo também a palavra escrita, ou a escrita traduzindo a oralidade em uma relação mútua de construção de significados.

Partindo desse pressuposto, conseguimos trazer planejamentos para aula e mostrar aos alunos como a contação de história é reinventada a partir das relações intersemióticas, e como a literatura se aproveita dessa relação. Este trabalho foi um esforço conjunto de promover uma discussão crítica do texto poético, levando os alunos de ensino superior a refletir sobre o trânsito temático da palavra poética no contexto da tradução e da contação de história, perspectiva crítica que foi refletida para o processo de letramento literário em sala de aula, atuando com textos que consideram a literatura oral e outras mídias. 
Demostrando que a contação de histórias sempre teve um papel determinante na educação e no processo de assimilação do texto literário, já que na antiguidade esse era o meio usado para passar conhecimento e formar o caráter do ser social. E também em pensar a contação de história como um processo dialógico.

Também trouxemos para sala de aula o poema Morte e vida Severina: auto de natal pernambucano, de João Cabral de Melo Neto, e sua adaptação para o desenho animado dirigido por Afonso Serpa, com realização da Fundação Joaquim Nabuco e TV Escola. O poema, desde sua publicação, já recebeu várias adaptações: no teatro, no cinema, e para a história em quadrinhos. Esta última, produzida por Miguel Falcão, foi tomada como base para a realização da animação que apresentamos aos alunos, para uma discussão fundamentada na animação e suas características peculiares.

Ao transpor o poema em imagens, o diretor utiliza o contraste de claro-escuro de forma criativa. Assim, elementos presentes no texto verbal, como a circularidade do percurso, a diluição da individualidade e as vozes discordantes, são traduzidos pelo uso da luz como recurso discursivo, tornando-a, dessa maneira, constituinte do texto visual, adquirindo a feição de uma verdadeira personagem.

Já sobre a cantiga e o poema "Na rua do sabão", de Manoel Bandeira, partindo de um refrão tão popular (afinal, que não conhece "Cai cai balão/ Cai cai balão/ Na rua do sabão"?), Bandeira retoma imagens da sua infância, possivelmente versificando um episódio que viveu enquanto criança, ativando, assim, a memória de todos nós. Com elementos do cotidiano crianças soltando balões (a despeito da proibição) e correndo atrás deles, Bandeira escreve o poema em versos livres, inspirado pelo espírito modernista.

Porém, se por um lado o poema traz memórias distantes aos adultos que os leem, ele também é muito bem recebido pelo público infantil. E é isso que nos faz pensar a literatura como ponto civilizador de humanista da nossa sociedade. Soltar balões já não faz parte dos costumes atuais (ainda bem!), mas soltar pipa ainda continua encantando os pequenos, que se reconhecem nos versos desse poema, além de identificarem o refrão de uma cantiga tão popular, o que reverbera uma atualidade a nossa formação cultural.

O poeta busca incansavelmente aquilo que se conserva em sua memória, as lembranças da meninice e a recordação das histórias, e traz quadrinhas do imaginário popular, como exemplo do poema "Na rua do sabão". A infância em Bandeira remete à experiência e está à narração e ao discurso poético. O poeta enquanto contador de histórias observa as ruas, 
procurando um diferencial para sua produção poética, buscando nas narrativas líricas, o fio da significação da existência, a fim de transmitir às gerações futuras seu aprendizado, que através da infância e da ternura para com os pobres.

\section{Conclusão}

Concluímos a pesquisa com resultados valorativos advindo da oficina de teatro ofertada pelo nosso grupo de pesquisa e das discussões centradas na prática da contação de histórias, promovendo resultados de letramentos observados nas aulas práticas coordenadas, ressaltando a importância de uma leitura dialógica do texto literário.

Por isso, o foco no letramento literário tendo como objeto de estudo o texto poético é um dos caminhos possíveis para que a escola consiga exercer seu papel de formadora de cidadãos capazes de valorizar a literatura como forma de compreensão do mundo.

A poesia e a contação de histórias é capaz de encantar, aguçar desejos, alegrar e é isso que a escola atualmente tem sentido necessidade, que estimule seus estudantes a ter interesse pelo ensino e aprendizagem. Revelando a busca incansável daquilo que se conserva em sua memória, as lembranças que formam nossa personalidade e a recordação das histórias.

Para Halbwachs (1990, p.24), "nossas lembranças permanecem coletivas, e elas nos são lembradas pelos outros, mesmo quando se trate de acontecimentos nos quais só nós estivemos envolvidos, e com objetos que só nós vimos." Em outras palavras, o filósofo chama a nossa atenção para o mecanismo dialógico da memória coletiva, ou seja, o que está no outro, mas acorda a nossa consciência mnemônica como uma música, um poema, um objetivo, uma paisagem natural e até mesmo a memória do outro, cujo desenvolvimento de um ponto de vista nos faz acessar a nossa própria memória, o que gera uma intersecção chamada de lembrança fictícia, pois nossa memória agora está misturada com a do outro, por isso ela tem um elemento ficcional. Tal movimento cria um aglomerado de imagens, possibilitando novas consciências e novos sentidos. Diante dessa conjectura, podemos dizer que uma das funções motivadoras da contação de história através da poesia é essa intersecção de memórias, responsável por criar a lembrança fictícia, e assim alargar o alcance de compreensão do leitor.

Buscamos, por meio dessa pesquisa, incentivar uma compreensão alargada do fenômeno literário, instrumentalizando criticamente o bolsista enquanto leitor e mediador do texto literário. Possibilitando um letramento científico e literário, de modo que ele possa ter 
uma base teórica para refletir a leitura e o ensino de Literatura seja na educação básica, seja no ensino superior. Nossa proposta ainda é relevante, na medida em que insere outros alunos de Letras da Uneal no processo de interação com a pesquisa por meio das oficinas, das aulas e da participação na peça teatral.

\section{Referências}

ABRAMOVICH, Fanny. Literatura infantil: gostosuras e bobices. $5^{\circ}$ ed. São Paulo: Scipione, 2001.

ALVES, Hélder Pinheiro. "Teoria da Literatura, crítica literária e ensino". In: Literatura: da crítica à sala de aula. Hélder Pinheiro e Marta Nóbrega (organizadores). Campina Grande: Bagagem, 2006.

BAKHTIN, Mikhail. Questões de literatura e de estética: a teoria do romance. Aurora F. Bernardini (tradução). São Paulo: Hucitec, 2002.

BANDEIRA, Manuel. Estrela da vida inteira. Rio de Janeiro: J. Olympio, 1976.

BANDEIRA, Manuel. Itinerário de Pasárgada. - 7. ed. - São Paulo: Global, 2012.

BOSI, Alfredo. O ser e o tempo da poesia. São Paulo: Companhia das Letras, 2000.

BUSATTO, Cléo. A Arte de Contar Histórias no Século XXI - tradição e ciberespaço. Rio de Janeiro: Vozes, 2005.

CANDIDO, Antonio. O direito à literatura. In: Vários escritos. São Paulo: Duas Cidades, 1995.

CHEVALIER, Jean \& GHEERBRANT, Alain. Dicionário de símbolos. Carlos Sussekind (tradução). Rio de Janeiro: José Olympio, 1998.

COSSON, Rildo. Letramento literário: teoria e prática. São Paulo: Contexto, 2007.

COUTINHO, Afrânio. Crítica e Teoria Literária. Rio de Janeiro: UFC, 1982.

HALBWACHS, Maurice. A memória coletiva. Tradução de Laurent Léon Schaffter. São Paulo: Vértice/ Revista dos Tribunais, 1990.

HUTCHEON, Linda. Uma teoria da adaptação. André Cechinel (tradução). Florianópolis: UFSC, 2011.

KLEIMAN, Angela. Leitura, ensino e pesquisa. São Pontes: Pontes, 1989. 
KRISTEVA, Julia. Introdução à semanálise. Lúcia Helena França Ferraz (tradução). São Paulo : Perspectiva, 2005.

MATOS, Gislayne Avelar. Contadores de histórias, essa gente de maravilhas. In: A palavra do contador de histórias. São Paulo: Martins Fontes, 2005.

MÜLLER, Adalberto. Linhas imaginárias: poesia, mídia e cinema. Porto Alegre: Sulina, 2012.

NETO, João Cabral de Melo. Morte e Vida Severina e Outros Poemas para vozes. Rio de Janeiro: Nova Fronteira, 2006.

PLAZA, Julio. Tradução Intersemiótica. São Paulo: Perspectiva, 2003.

SANTOS, Idelette Fonseca \& BATISTA, Maria de Fátima (org.). Cancioneiro da Paraíba. João Pessoa: GRAFSET, 1993.

STAM, Robert. A literatura através do cinema: realismo, magia e arte de adaptação. Tradução de Marie-Anne Kremer e Gláucia Renate Gonçalves. Belo Horizonte: Editora UFMG, 2008.

TIERNO, G. (org.) A Arte de Contar Histórias: abordagens poética, literária e performática. São Paulo: Ícone, 2010.

KEFALÁS, Eliana. Corpo a corpo com o texto no ensino de literatura. Campinas: Autores Associados, 2012 